\title{
Cytogenetic Biomonitoring in Buccal Mucosal Cells from Municipal Solid Waste Collectors
}

\author{
MARIANA CARVALHO ANDRADE ${ }^{1}$, JEAN NUNES DOS SANTOS ${ }^{1}$, PATRICIA RAMOS CURY ${ }^{1}$, \\ ANA CAROLINA CORREA FLYGARE ${ }^{2}$, SAMUEL RANGEL CLAUDIO ${ }^{2}$, \\ CELINA TIZUKO FUJIYAMA OSHIMA ${ }^{3}$ and DANIEL ARAKI RIBEIRO ${ }^{2}$ \\ ${ }^{1}$ Post-graduate Program in Dentistry and Health, Federal University of Bahia, UFBA, Salvador, Brazil; \\ ${ }^{2}$ Department of Biosciences, Federal University of Sao Paulo, UNIFESP, Santos, Brazil; \\ ${ }^{3}$ Department of Pathology, Paulista Medical School, UNIFESP, São Paulo, Brazil
}

\begin{abstract}
Waste collectors collect, transport, and process the garbage produced by people living in the city. Nowadays, this activity requires special attention due to the environmental impact of garbage and its potential consequences on human health. The aim of this study was to evaluate potential cytotoxic and mutagenic effects of garbage collection on waste collectors. For this purpose, a total of 47 male waste collectors aged from 24 to 53 years were included in the experimental group. A total of 30 men matched by age were used as the control group. Cytotoxicity and mutagenicity were analyzed by micronucleus test in buccal mucosal cells. No statistically significant difference $(p>0.05)$ in the frequency of micronuclei was detected in the waste collectors when compared to controls. Nevertheless, higher frequencies of karyolysis and pyknosis $(p<0.05)$ were detected in buccal mucosaI cells from waste collectors when compared to matched controls. Taken together, our results indicate that waste collectors comprise an at-risk group as a result of increased cytotoxicity apparent from buccal mucosa cells.
\end{abstract}

Waste collectors collect, transport, and process the garbage produced by people living in the city. Nowadays, this activity requires special attention due to the environmental impact of garbage and its potential consequences on human health (1). It is known that waste collectors handle many hazardous materials, from physical, chemical or even biological

Correspondence to: Daniel Araki Ribeiro, DDS, Ph.D., Departamento de Biociências, Universidade Federal de São Paulo UNIFESP, Av. Ana Costa 95, Zip code: 11060-001, Santos - SP, Brazil. Tel/Fax: +55 1338783823, e-mail: daribeiro@unifesp.br, daribeiro@pesquisador.cnpq.br

Key Words: Oral mucosa cells, waste collectors, micronucleus test, biomontoring. sources. Some studies have been conducted to evaluate the impact of this occupational exposure; the results showed that waste collectors present respiratory symptoms induced by dust and microorganisms; gastrointestinal disorders such as nausea and diarrhea induced by bad odors; as well as body injuries (2-7). Of particular importance, waste collectors can also be exposed to bioaerosols, gases, and vapors that in turn can induce many injuries in eukaryotic cells $(8,9)$. For this reason, it is probable that adverse health effects induced by garbage exposure depend strongly on the scenario of occupational exposure. In order to understand the true consequences of such workers under different paradigms, it is mandatory to estimate the risk faced by those continuously exposed to genotoxic agents under different scenarios and the effects of their exposure to these agents at the cellular and molecular level.

The micronucleus test using buccal mucosal cells was standardized by Belien et al. as a cheap and non-invasive biomarker for evaluating cytogenetic damage (10). Today, this methodology is recommended in human biomonitoring studies for predicting risk assessment $(11,12)$. This is because some investigations have shown that higher micronuclei frequencies in eukaryotic cells of independent origin are correlated with an elevated risk of cancer. Micronuclei are defined as acentric fragments or whole chromosomes that are not included in the main nuclei of the daughter cells. Micronuclei are induced by substances that cause chromosomal breakage (clastogens), or disruption of the spindle apparatus (aneugens) (10). Tolbert et al. (13) increased the specificity of this test by analyzing other metanuclear alterations indicative of cytotoxicity, such as pyknosis, karyolysis and karyorrhexis.

Because of the lack of scientific evidence regarding the effects of garbage exposure in waste collectors, the aim of this study was to investigate mutagenicity and cytotoxicity in buccal mucosal cells from waste collectors by micronucleus assay. 


\section{Materials and Methods}

Participants. This study was conducted at a garbage collection company in Salvador, BA, Brazil. The subjects of this study consisted of 47 men aged 24 to 53 years (mean $\pm S D=36 \pm 8.5$ years). The study's eligibility criteria included: (i) having worked at least 1 year as a waste collector; (iii) 18-55 years of age; and (iii) consent to participate in the study. The control group consisted of 30 healthy men matched by age to the members of the experimental group aged (33.6 \pm 11.6 years), not exposed directly to garbage. Each person was interviewed concerning possible confounding factors and individuals were excluded from this study when there was any lesion on the oral mucosa visible at clinical examination, a history of cancer, previous radio- or chemotherapy, use of therapeutic drugs, or exposure to diagnostic X-rays during the previous 6 months. None of volunteers were smokers. Exposure to other known genotoxic agents such as alcohol consumption was not recorded in this setting. The study was approved by the Ethics Committee of the Federal University of Bahia, Brazil. Informed consent was obtained from the individuals included in the study.

Micronucleus test on oral mucosal cells. After rinsing the mouth with tap water, cells were obtained from each participant by scraping the mucosa of the right/left cheek with a moist wooden spatula. Cells were transferred to a tube containing saline solution, which was then centrifuged $(85 \times g)$ for $5 \mathrm{~min}$, fixed in $3: 1$ methanol/acetic acid, and dropped onto pre-cleaned slides. After that, the air-dried slides were stained using the Feulgen/Fast-Green method, and examined under a light microscope at $\times 1,000$ magnification to determine the frequency of micronucleated cells. Two thousand cells were scored from each person.

Data analysis. Micronuclei were scored according to the criteria described by Belien et al. (10) as a parameter of DNA damage (mutagenicity). For cytotoxicity, the following nuclear alterations were considered: pyknosis, karyolysis and karyorrhexis. Results were expressed as a percentage of total cells examined. This analysis was established in a previous study conducted by our research group (14). The analysis was evaluated independently by two biomedical doctors in a blinded fashion.

Statistical methods. The Mann-Whitney non-parametric test was used to compare the frequencies of cytotoxicity among the samples between the experimental group versus the control group. Micronucleus frequencies between controls and waste collectors were evaluated as established by Pereira et al. (14). The statistical analysis was conducted using BioStat software, version 5.0 (Maringa, PR, Brazil). The level of statistical significance was set at $5 \%$.

\section{Results}

Table I shows the frequency of micronucleated cells in buccal mucosaI cells of waste collectors. No significant statistically significant differences $(p>0.05)$ in frequency were obtained between the experimental group and matched controls.

When cytotoxicity parameters were evaluated, interesting findings were made. Continuous exposure to garbage induced cytotoxicity in buccal mucosal cells, since the
Table I. Micronucleus incidence (mean $\pm S D$ ) in buccal mucosal cells of waste collectors.

\begin{tabular}{lc}
\hline Group & Micronucleus incidence \\
\hline Controls $(\mathrm{n}=30)$ & $0.07 \pm 0.02$ \\
Waste collectors $(\mathrm{n}=47)$ & $0.03 \pm 0.1^{*}$ \\
\hline
\end{tabular}

${ }^{*} p>0.05$ when compared to the control group.

Table II. Cytotoxicity (mean $\pm S D)$ as reflected in the frequency of karrhyorexis, pyknosis and karyolysis in buccal mucosa cells of waste collectors as a percentage of total cells examined.

\begin{tabular}{lccc}
\hline Group & Pyknosis & Karrhyorexis & Karyolysis \\
\hline Controls $(\mathrm{n}=30)$ & $9.1 \pm 4.8$ & $1.0 \pm 0.9$ & $1.9 \pm 1.7$ \\
Waste collectors $(\mathrm{n}=47)$ & $16.2 \pm 5.3^{*}$ & $0.7 \pm 0.8$ & $13.5 \pm 9.4^{*}$ \\
\hline
\end{tabular}

${ }^{*} p<0.05$ when compared to the control group.

frequency of pyknosis was almost two-fold and karyolysis more than six-fold $(p<0.05)$ in buccal mucosaI cells from waste collectors than in those from the controls. Karrhyorexis did not differ remarkably between the groups $(p>0.05)$ (Table II).

Finally, exposure to known genotoxins was not investigated since all participants were non-smokers.

\section{Discussion}

The aim of this study was to investigate chromosomal damage and cellular death induced by occupational exposure to municipal garbage as indicators of mutagenicity and cytotoxicity, respectively. The investigation was conducted using the micronucleus test in exfoliated oral cells. To the best of our knowledge, this approach has not been used so far.

The micronucleus assay is widely applied by the scientific community since it represents an easy, cheap and reproducible method when evaluating cytogenetic damage in human populations (10). Micronuclei possess genetic material that was not incorporated into the main nucleus during mitosis, as a result of chromosomal breakage or loss (10). Pathobiological events that induce micronuclei occur in the basal layer of the epithelial tissue because cell duplication occurs in this layer. Programmed turnover of epithelial tissues brings such cells to the surface where they exfoliate and therefore, it is possible to detect micronuclei, as well as other metanuclear alterations, under subjective microscopic analysis using specific DNA stain (10).

Genomic damage plays an important role during mutagenesis and carcinogenesis. It has been well established that genomic damage is produced by environmental exposure 
to mutagens, carcinogens, and inherited genetic factors such as defects in xenobiotic metabolism and DNA repair deficiency (15). Micronuclei characterize genomic instability in cells and living tissues (16). The detection of an elevated frequency of micronuclei indicates an increased risk for developing chronic degenerative diseases, including cancer (17). Our results demonstrated the absence of statistical significance for micronucleus frequency in buccal cells of waste collectors when compared to those from matched controls. By comparison, some studies have demonstrated increased frequencies of micronuclei in such cells from agricultural workers exposed to pesticide mixtures in Guerrero state, Mexico (18). On the other hand, no induction of micronucleated cells was observed in buccal epithelia in people exposed to wood dust (19). Similarly, residents in Vietman did not show remarkable differences for micronucleus frequency in buccal mucosa cells after 40 years of dioxin exposure (20). It seems that chronic exposure to known genotoxins modulates the cytogenetic status of exposed groups. This could explain our negative results. Overall, further studies are welcome to elucidate this issue.

In order to monitor cytotoxic effects, the frequencies of karyorrhexis, karyolysis and pyknosis were included in this study. Our results showed that contact with garbage increased the frequency of pyknosis and karyolysis. Therefore, such findings revealed that continuous exposure to garbage induces a cytotoxic effect indicative of necrosis. It has been established that chromatin shrinkage followed by disruption of the nuclear membrane may result in cytotoxicity (21). Some authors have postulated that chronic exposure to genotoxins induced an increase in cell death in buccal epithelium of humans $(19,20)$. Our results are fully in agreement with these findings. It is important to stress that cytotoxicity interferes with micronucleus occurrence, as it is known that such frequency generally declines when genotoxic agents reach cytotoxic levels (21). Taken together, we assume that continuous exposure to garbage induces cytotoxicity as a result of necrosis in buccal mucosa cells.

Karryorexis did not duffer remarkably between the two groups. These results are totally new and difficult to interpret since the frequency of pyknosis and karyolysis were increased in the experimental group. An increases in karryorexis is closely associated with apoptosis. Apoptosis is an important biological process in coordinated cell death, which is genetically controlled for tissue homeostasis (22) Overall, such findings demonstrated that garbage collection does not appear to induce any apoptotic response in buccal cells.

In conclusion, the results of the present study suggest that exposure to garbage induces cyototoxic damage in buccal mucosal cells. Such cytotoxicity represents a degree of risk of carcinogenesis, particularly via non-genotoxic mechanisms. This reinforces the need to evaluate the side-effects on health induced by occupational exposure to garbage. Overall, waste workers should be examined regularly in order to prevent some diseases related to continuous chemical or biological exposure.

\section{Conflicts of Interest}

None declared.

\section{References}

1 Vimercati L, Baldassarre A, Gatti MF, De Maria L, Caputi A, Dirodi AA, Cuccaro F and Bellino RM: Respiratory health in waste collection and disposal workers. Int J Environ Res Public Health 13(7): 2016, pii: E631 .

2 Tsujimura $\mathrm{H}$, Taoda $\mathrm{K}$ and Kitahara T: A field study on the physiological workload of garbage collectors in the Japanese summer. Ind Health 50(6): 556-566, 2012.

3 Allmers $\mathrm{H}$, Huber $\mathrm{H}$ and Baur X: Two year follow-up of a garbage collector with allergic bronchopulmonary aspergillosis (ABPA). Am J Ind Med 37(4): 438-442, 2000.

4 de Meer G, Heederik D and Wouters IM: Change in airway responsiveness over a workweek in organic waste loaders. Int Arch Occup Environ Health 80(7): 649-652, 2007.

5 Eskezia D, Aderaw Z, Ahmed KY and Tadese F: Prevalence and associated factors of occupational injuries among municipal solid waste collectors in four zones of Amhara region, Northwest Ethiopia. BMC Public Health 16(1): 862, 2016.

6 Reddy EM and Yasobant S: Musculoskeletal disorders among municipal solid waste workers in India: A cross-sectional risk assessment.J Family Med Prim Care 4(4): 519-524, 2015.

7 Eassa SM, El-Wahab EW, Lotfi SE, El Masry SA, Shatat HZ and Kotkat AM: Risk factors associated with parasitic infection among municipality solid-waste workers in an Egyptian community. J Parasitol 102(2): 214-221, 2016.

8 Lee KH, Jung HJ, Park DU, Ryu SH, Kim B, Ha KC, Kim S, Yi $\mathrm{G}$ and Yoon $\mathrm{C}$ : Occupational exposure to diesel particulate matter in municipal household waste workers. PLoS One 10(8): e0135229, 2015.

9 Tschopp A, Bernard A, Thommen AM, Jeggli S, Dumont X, Oppliger A, Hotz P: Exposure to bioaerosols, respiratory health and lung-specific proteins: a prospective study in garbage and wastewater workers. Occup Environ Med 68(11): 856-859, 2011.

10 Beliën JA, Copper MP, Braakhuis BJ, Snow GB and Baak JP: Standardization of counting micronuclei: definition of a protocol to measure genotoxic damage in human exfoliated cells. Carcinogenesis 16(10): 2395-2400, 1995.

11 OECD TG 474: OECD Guideline for the Testing of Chemicals, No. 474: Mammalian Erythrocyte Micronucleus Test. Organization for Economic Cooperation and Development: Paris, France, 1997.

12 OECD TG 487: OECD Guideline for the Testing of Chemicals, No. 487: In vitro Mammalian Cell Micronucleus Test (MNvit). Organization for Economic Cooperation and Development: Paris, France, 2009.

13 Tolbert PE, Shy CM and Allen JW: Micronuclei and other nuclear anomalies in buccal smears: methods development. Mutat Res 271: 69-77, 1992. 
14 Pereira, CAB: Teste estatístico para comparar proporções em problemas de citogenética. In: Rabelo-Gay N, Rodrigues MA and Monteleone-Neto R (eds.) Mutagênese, Teratogênese e Carcinogênese. SBG, pp. 113-121, 1991 (in Portuguese).

15 Thomas P, Harvey S, Gruner T and Fenech M: The buccal cytome and micronucleus frequency is substantially altered in Down's syndrome and normal ageing compared to young healthy controls. Mutat Res 638: 3-47, 2008.

16 Stich HF and Rosin MP: Quantitating the synergistic effect of smoking and alcohol consumption with the micronucleus test on human buccal mucosa cells. Int J Cancer 31: 305-308, 1983.

17 Kujan O, Oliver RJ, Khattab A, Roberts SA, Thakker N and Sloan A: Evaluation of a new binary system of grading oral epithelial dysplasia for prediction of malignant transformation. Oral Oncol 42: 987-993, 2006.

18 Carbajal-López Y, Gómez-Arroyo S, Villalobos-Pietrini R, Calderón-Segura ME and Martínez-Arroyo A: Biomonitoring of agricultural workers exposed to pesticide mixtures in Guerrero state, Mexico, with comet assay and micronucleus test. Environ Sci Pollut Res Int 23(3): 2513-2520, 2016.

19 Wultsch G, Nersesyan A, Kundi M, Wagner KH, Ferk F, Jakse $\mathrm{R}$ and Knasmueller S: Impact of exposure to wood dust on genotoxicity and cytotoxicity in exfoliated buccal and nasal cells. Mutagenesis 30(5): 701-709, 2015.
20 Sycheva LP, Umnova NV, Kovalenko MA, Zhurkov VS, Shelepchikov AA and Roumak VS: Dioxins and cytogenetic status of villagers after 40 years of Agent Orange application in Vietnam. Chemosphere 144: 1415-1420, 2016.

21 Cerqueira EM, Gomes-Filho IS, Trindade S, Lopes MA, Passos JS and Machado-Santelli GM: Genetic damage in exfoliated cells from oral mucosa of individuals exposed to X-rays during panoramic dental radiographies. Mutat Res 562(1-2): 111-117, 2004.

22 Paronetto MP, Passacantilli I and Sette C: Alternative splicing and cell survival: from tissue homeostasis to disease. Cell Death Differ 23(12): 1919-1929, 2016.
Received November 23, 2016

Revised December 24, 2016

Accepted January 10, 2017 